\title{
INTERDISCIPLINARIDADE NA SAÚDE PÚBLICA: UM CAMPO EM CONSTRUÇÃO
}

Romeu Gomes *

Suely Ferreira Deslandes **

O presente artigo, baseado numa revisão bibliografia, tem como objetivo discutir a questão da interdisciplinaridade no Campo da Saúde Pública (sua necessidade, obstáculos a sua implementarão e possibilidades). Para isso, inicialmente, é apresentado um debate em termos conceitual e histórico que explicita a temática. Neste segmento é discutida a inclusão e a exclusão da interdisciplinaridade no Campo da Saúde Pública, assim como as diferentes dimensões desta. Em seguida é relatada uma experiência interdisciplinar no Campo da Saúde Pública. Finalmente, conclui-se que a interdisciplinaridade é extremamente necessária para a Saúde Pública dada a complexidade de seu objeto.

UNITERMOS: interdisciplinaridade, Saúde Pública

\section{1 - PALAVRAS INICIAIS}

Falar de interdisciplinaridade, atualmente, parece ser uma discussão amplamente aceita. Contudo, tanto em termos conceituais, quanto em relação a validade do assunto, não há um consenso firmado nos meios acadêmicos sobre isso. Assim, a título de melhor situarmos a presente temática, parece ser necessário analisarmos os conceitos de interdisciplinaridade focalizando-a Saúde Pública.

A partir dessa perspectiva, afigura-se como objetivo do presente artigo a discussão da interdisciplinaridade no campo da Saúde Pública, entendendo-a como uma necessidade intrínseca a complexidade de seu

\footnotetext{
*Professor Adjunto da UERJ. Pesquisador do CLAVES/ENSP/FIOCRUZ

**Professora do Departamento de Sociologia UFF. Pesquisadora do CLAVES/ ENSP/FIOCRUZ
} 
objeto e como uma proposta de resgate da medida do humano na racionalidade técnicocientífica.

Tentamos, num primeiro momento, discutir algumas questões sobre a interdisciplinaridade: seus posicionamentos, obstáculos, críticas e proposições para sua realização. Num segundo momento, refletimos sobre a interdisciplinaridade a luz da Saúde Pública, sua trajetória e obstáculos. Num terceiro item, trazemos o relato de uma experiência na Saúde Pública, a do Centro Latino Americano de Estudos de Violência e Saúde - CLAYES, que tem buscado na prática interdisciplinar uma alternativa às limitações de enfoques unidisciplinares.

Por fim, a título de promovermos a continuação do debate, discutimos pressupostos, enquanto pontos de reflexão, para um aprofundamento do assunto.

\section{2 - A INTERDISCIPLINARIDADE: UMA QUESTÃO POLÊMICA}

A interdisciplinaridade não é uma perspectiva inteiramente nova diante da construção do conhecimento. Contudo, a partir do século XIX, com o avanço da ciência como expressão máxima da racionalidade humana, há também um processo crescente de disciplinarização e conseqüentemente um grande recuo desta proposta interdisciplinar.

O positivismo se tornou hegemônico enquanto paradigma do saber no mundo moderno e as disciplinas começaram a se afirmar de forma isolada. Em decorrência disso, surgiu uma excessiva especialização que resultou numa fragmentação do saber $\left(M I N A Y O^{15}\right)$. Assim, a interdisciplinaridade, enquanto uma proposição do conceber e fazer ciência somente ressurge no século XX, já nos fins da década de 50 , quando se coloca mais claramente em discussão a necessidade de uma proposta epistemológica de caráter interdisciplinar.

Em Minayo15, fica claro que a interdisciplinaridade pode significar uma panacéia epistemológica para curar os males da ciência moderna, ou pode ser abordada a partir de um ceticismo radical, ou ainda pode ser vista como uma fatalidade própria do avanço técnico e científico. Com base no pressuposto de que a temática se expressa enquanto uma questão polêmica, a autora citada promove o debate entre diferentes posicionamentos sobre o assunto. Entre eles, ressaltamos os que são representados pelos nomes de Gusdorf, Carneiro Leão e Habermas. Utilizando as considerações de Minayo sobre esses três posicionamentos, sintetizamos a discussão sobre a temática e/ou questão. 
Gusdorf $^{9}$, um humanista e defensor da interdisciplinaridade, coloca que antes da ciência moderna, a sociedade encontrava no conjunto de seus mitos e cosmogonias os elementos de uma inteligibilidade universal. A produção do conhecimento e as formas de explicação e intervenção no real tinham uma significação humana. A ciência moderna, com a disciplinarização, fragmenta a percepção do humano e, distanciando-se dele, reduz a existência humana a um estatuto de perfeita objetividade. Assim, a ciência moderna, ao recortar o mundo das vivências (natureza) e o do vivido (humano) em inúmeros objetos, sob administração das diversas disciplinas, produz um conhecimento esquizofrênico. Para Gusdorf $^{9}$ todas as ciências são as ciências do humano, portanto, a ciência que dissocia e desintegra seu objeto pode ser considerada alienada e alienante.

Contra este caráter "doentio" e do conhecimento fragmentado em ilhas e sem a face humana, insurge-se a interdisciplinaridade como a busca de totalidade do conhecimento, como uma crítica veemente à sua fragmentação; à institucionalização e aprisionamento do saber nas academias e à crescente valorização "per si" do saber técnico (MINAYO ${ }^{13}$ ).

A interdisciplinaridade, portanto, conduz a uma profunda reflexão sobre o conceito de ciência. Por outro lado, como afirma Japiassu ${ }^{11}$, também pode ser vista como uma necessidade interna da ciência, a fim de resgatar a unidade de seu objeto e os vínculos de significação humana. Mas coloca-se também, segundo o autor, como uma necessidade imposta pelos complexos problemas que são colocados para a ciência e que não são respondidos por enfoque unidisciplinar ou pela justaposição de várias disciplinas.

Gusdorf $^{9}$, portanto, considera a interdisciplinaridade como uma tarefa filosófica que conclamaria o saber científico a uma conversão ética e aglutinadora em prol da integração do conhecimento, buscando os limites e os elementos gerais e comuns de cada disciplina. (MINAYO ${ }^{13}$ ).

Tal proposta, embora correta em seus anseios, sofre de uma limitação de magnitude, atribuindo até certo ponto a uma disposição "voluntária" daqueles que produzem o conhecimento técnico e científico.

Contudo, Gusdorf ${ }^{9}$ coloca em discussão aspectos de grande importância, levandonos a reflexão que o desafio interdisciplinar deve basear-se numa perspectiva de diálogo e interação das disciplinas, para além das tentativas multidisciplinares (ainda que possam ser vistas como uma etapa para a interdisciplinaridade) que apenas produzem conhecimentos justapostos em tomo de um mesmo problema, cada qual a partir de seu próprio e inviolável ponto de vista. Com base nesta reflexão, propomos um diálogo, de tal forma que as disciplinas saiam enriquecidas em nível de método e perspectiva. (Trata-se, enfim, de uma proposta de religare, não para a dimensão divina, mas entre o conhecimento científico e a complexidade do mundo vivido, para a 
medida do humano na produção da ciência, visando a superação da dicotomia entre o conhecimento teórico e o prático).

Já Carneiro Leao ${ }^{3}$ parte de um ponto diferente de Gusdorf. Sua crítica é centrada na ciência moderna que busca uma uniformização cada vez maior de suas estruturas. Voltada para a padronização, enquanto movimento de difusão de si mesma, atropela diferenças e oposições. Segundo Leão, o conceito central da ciência moderna é a funcionalidade.

Dentro desse raciocínio:

"a ciência é uma forma de conhecimento que reduz tudo que está sendo, o que está vindo a ser, a funções, inclusive o sujeito e as relações entre sujeito e objeto" (MINAYO $\left.{ }^{15}\right)$.

Para ele, o universo do simbólico, do vivido, do indivíduo e da sociedade foi sendo reduzido pela racionalidade científica a um único universo: o dos objetos e dos sujeitos de apresentação e representação, sendo esses os únicos elementos a valerem como real. Nesse processo de crescente uniformalização de estruturas, o real se reduz a dispositivos, obedecendo exclusivamente a funcionalidade da ciência e da técnica, sendo que essas tornam cada vez mais indissociadas.

Nessa perspectiva, a interdisciplinaridade é vista como um processamento funcional, uma tecnologia que pode garantir a expansão de práticas operatórias comprometidas com a transformação do real em objetividade, ou seja, garantindo assim a essência da ciência e de sua lógica de funcionalidade.

Assim, Carneiro Leao ${ }^{3}$ está mais preocupado em questionar a ciência enquanto forma de conhecimento que, ao padronizar a verdade, afasta o ser humano de sua essencialidade, do que refletir sobre a fragmentação científica. Ele critica a importação de modelos culturais do primeiro mundo. Mostra que o poder e a dominação são acenados através das atuais retóricas "da inter e da transdisciplinaridade "importadas" sob a forma de modelos econômicos, paradigmas políticos, recursos tecnológicos e matrizes de conhecimentos" (MINAYO ${ }^{15}$ ).

O terceiro posicionamento sobre a temática em questão, destacado em MINAYO ${ }^{16}$, se vincula ao nome de Habermas. Esse posicionamento também realiza uma crítica da ciência, partindo, no entanto, de sua positividade. Habermas aposta numa nova racionalidade que contemplaria o encontro entre filosofia, ciência e mundo. Defendendo essa nova racionalidade, ele se contrapõe a razão instrumental. Através de sua teoria do agir comunicativo, ele desenvolve a "crítica ao estreitamento do conceito de racionalidade as suas dimensões congnitivo-instrumentais, deixando de fora os elementos ético-normativos" (MINAYO ${ }^{15}$ ).

Assim como Gusdorf, Habermas também vê a filosofia como saída para combater esse estreitamento. Entretanto, o posicionamento desse último apresenta características 
distintas. Em sua teoria a filosofia crítica se apóia na atividade comunicativa e na razão comunicativa. A partir desse pressuposto:

"A filosofia não reduziria seu papel a um posicionamento apenas crítico, mas ampliaria sua atividade num labor cooperativo, fazendo mediação entre a filosofia e as ciências, entre a cultura sofisticada dos especialistas nas ciências e técnicas e o mundo vital" (MINAYO $\left.{ }^{15}\right)$.

A filosofia, além de crítica, se caracterizaria por um processo de cooperação interdisciplinar, assumindo um papel mediador entre ciência e mundo da vida cotidiana.

Nessa perspectiva, o sujeito cognoscente não se relaciona externamente com os objetos a fim de dominá-los, mas está em interação com outros sujeitos preocupando-se com o significado do conhecimento.

Os três posicionamentos sistematizados apontam para o fato de que a experiência interdisciplinar não é uma proposta fácil, sua definição e operacionalização ainda são pontos em debate. Muitas são as dificuldades e obstáculos impostos.

\section{3 - A INTERDISCIPLINARIDADE NO CAMPO DA SAÚDE PÚBLICA}

O campo da Saúde Pública foi demarcado historicamente por um modelo positivista, onde a doença vista como desvio e ameaça anômica a ordem e estrutura social era tratada basicamente através de uma ótica biocêntrica.

A integração das ciências sociais nos currículos de medicina há cerca de três décadas atrás, não alterava muito tal quadro uma vez que o enfoque era predominantemente funcionalista, fortemente influenciado por Talcott Parsons. $\mathrm{Na}$ prática, tais disciplinas acabavam por serem vistas como ciências da conduta ou comportamentais, sendo assim tidas como saberes meramente complementares. $\left(\mathrm{GARCIA}^{8}, \mathrm{ABEMO}^{1}\right)$.

$\mathrm{Na}$ década de 60, algumas experiências como a da Medicina Comunitária, nos EUA e a tentativa de interdisciplinaridade na área de Saúde Mental na Europa, apontavam uma nova perspectiva de articulação entre as disciplinas sociais e biomédicas, embora já se constatassem obstáculos epistemológicos, psicossociais institucionais e de linguagem. $\left(A B E M O^{1}\right)$.

A década de 70 é marcada por profundas críticas ao modelo funcionalista na saúde. Em muitos países latinos, já se colocava o estudo da produção social das doenças, onde o adoecer era percebido através dos condicionantes econômicos, 
históricos e sociais. (GARCIA ${ }^{8}$ ). Apesar da ampliação de perspectivas, não pode-se dizer que houve um grande avanço para o diálogo interdisciplinar, muito embora já se questionasse, principalmente na década de 80 , a esterilidade do enfoque unidisciplinar, por mais abrangente que fosse sua análise.

Contudo, na década de 80 , fortemente influenciada pela participação dos movimentos sociais consagra-se o conceito ampliado de saúde, exigindo novas abordagens para a produção do conhecimento e para a intervenção prática.

O que também se coloca em debate é que na Saúde Pública, como campo político, o espaço de hegemonia de uma disciplina ou de articulação cooperativa entre disciplinas é um campo de correlação de forças, fortemente relacionado a consciência social e política que se engendra no confronto das práticas. Hoje, pode-se dizer que desfrutamos de um consenso acerca da inegável complexidade do objeto de Saúde Pública.

Frenk $^{7}$ assinala que na saúde confluem diferentes dimensões e aspectos. Numa dimensão há as instâncias do biológico e do social, em outras há o indivíduo e a comunidade e ainda em outra há a política social e a política econômica. Partindo desse pressuposto que a saúde é um meio de realização pessoal e coletiva, a Saúde Pública deve levar em conta esses diferentes prismas relacionados ao seu objeto.

Para esse autor, recentemente tem sido discutida a idéia de que a qualidade "pública" da expressão Saúde Pública se refere a uma dimensão de análise que consiste no nível populacional. Nesse sentido, "público" não é um conjunto de serviços em particular, nem uma forma de propriedade e nem ainda um tipo de problema.

A Saúde Pública, devido a sua natureza, se volta para uma perspectiva baseada em grupos sociais ou populações. Essa perspectiva inspira sua aplicação, seu conhecimento e seu âmbito de atuação. A partir do princípio multidisciplinar de investigação, podemos, assim, definir Saúde Pública como ampliação das ciências biológicas, sociais e da conduta ao estudo do fenômeno saúde em populações humanas.

Nessa perspectiva, o processo saúde-doença, como observam Birman² e RuffinoNeto $^{18}$, se traduz pela inter-relação entre aspectos de ordem clínica e sociológica. Assim, faz-se necessário levarmos em conta - além dos aspectos anatômicos e fisiológicos valores, atitudes e crenças que se encontram no universo das representações dos atores sociais que vivenciam esse processo.

Várias pesquisas citadas por McElroy e Townsend ${ }^{12}$, concluem que a compreensão dos problemas de saúde requerem, no mínimo, diferentes tipos de informações, sejam ambientais, clínicas, epidemiológicas, comportamentais, sociais e culturais sendo necessária uma abordagem ecológica dos problemas. 
Um exemplo bem contemporâneo em que estão presentes as relações saúdedoença-moral-sociedade se refere à AIDS. As investigações e as intervenções da Saúde Pública no âmbito dessa temática cada vez mais vêm contemplando a idéia de que "a doença e a medicina são possíveis de investimento no plano simbólico e são igualmente objeto de uma construção de sentido e de elaboração de um saber" (HERLZLICH \& PIERRET ${ }^{1}$ ).

Levando em conta esse exemplo e partindo de análises de Foucault ${ }^{4,5,6}$, ressaltamos, pelo menos, três aspectos centrais a serem compreendidos no campo da Saúde Pública: (a) o processo de construção de saberes; (b) a articulação desse processo com poderes presentes num tempo e num espaço determinados, e (c) o investimento simbólico enquanto causa e efeito dessa articulação. Na configuração desses aspectos, perpassam explícita ou implicitamente as relações tecidas entre o processo saúde-doença e a sociedade.

A partir dessas considerações e retomando as idéias de Frenk ${ }^{7}$, podemos concluir que, para se chegar a uma Saúde Pública, é preciso que haja um esforço interdisciplinar que tem como conseqüência uma abertura conceitual.

Alguns obstáculos à interdisciplinaridade no campo de Saúde Pública podem ser apontados. Podemos, de pronto, identificar obstáculos epistemológicos, institucionais e psicossociológicos tal como postula Gusdorf ${ }^{9}$. Correndo o risco de uma simplificação, podemos apontar ainda, alguns aspectos relacionados: (a) a forte tradição positivista e biocêntrica no tratamento dos problemas de saúde; (b) os espaços de poder que a disciplinarização significa; (c) a estruturação das instituições de ensino e pesquisa em departamentos, na maioria das vezes sem nenhuma comunicação entre si; (d) as dificuldades inerentes a experiência interdisciplinar tais como a operacionalização de conceitos, métodos e práticas entre as disciplinas.

\section{4 - BREVE RELATO DE UMA EXPERIÊNCIA}

A violência é hoje no Brasil, responsável pela principal causa da morte na faixa etária de 5 a 49 anos, sendo que de 15 a 29 anos ela atinge o alarmante percentual de $64,4 \%$ das mortes. Conseqüentemente, são as causas violentas as principais responsáveis pelos "anos de vida potencialmente perdidos" no país (MINAYO \& SOUZA $^{16}$ ). Tais fatos conferem, inegavelmente, a violência um caráter de sério problema de Saúde Pública.

A violência e seu impacto na saúde é a problemática na qual se 
debruça o Centro Latino Americano de Estudos de Violência e Saúde - CLAVES, criado em 1989 e vinculado à Fundação Oswaldo Cruz - Rio de Janeiro.

Afirmamos que a violência, tal como a saúde, pode ser considerada como um processo social complexo no qual intervêm fatores estruturais, ideológicos e culturais e, portanto, não pode prescindir de uma abordagem de cooperação entre as disciplinas.

A interdisciplinaridade toma-se, portanto, uma exigência imposta pela complexidade deste objeto o qual se articulam indissociavelmente aspectos biológicos, culturais, econômicos, psicológicos e sociais. Assim, coloca-se como necessária a integração entre as ciências sociais, epidemiologia, planejamento em saúde e psicologia, buscando-se a discussão de teorias, conceitos e métodos e a aproximação dos serviços, políticos e programas de saúde.

Diante de tamanha tarefa, temos tentado uma experiência interdisciplinar, ainda que em construção. Nessa interação, as ciências sociais contribuem com alguns marcos para a reflexão e que atravessam o método. (SOUZA, ASSIS \& DESLANDES ${ }^{19}$; MINAYO ${ }^{14}$ ):

(a) a violência é um fenômeno histórico e só pode ser entendida a partir das relações sociais específicas de determinada sociedade;

(b) a violência tem um caráter político revelador das estruturas de dominação (de classes, de grupos, de gêneros, de nações) e das contradições daquela sociedade;

(c) a violência tem um caráter cultural e ideológico que determina socialmente o que é considerado violento ou aceitável;

(d) a violência deve ser entendida como uma "rede" de relações, relacionando a violência dos indivíduos com a violência do Estado.

A epidemiologia, por exemplo, trazendo a contribuição da categoria de "causas externas" permite a visualização do impacto da violência na saúde, embora não perdendo de vista o grau de complexidade que envolve a delimitação e conceituação da violência. Assim, a epidemiologia colabora com as ciências sociais com seus indicadores para desconstruir a noção ideológica do fenômeno violência tomado unicamente como delinqüência (SOUZA, ASSIS \& DESLANDES ${ }^{19}$; MINAYO ${ }^{14}$ ). Por outro lado, também possibilita às ciências sociais trazer o debate político da necessidade de atuação no campo de saúde pública, uma vez que demonstra que a violência não é um fenômeno que atinge, excepcionalmente, a população, que não é "uma vivência de guetos".

As ciências sociais por sua vez propiciam a epidemiologia uma contextualização histórica, social e cultural de seus indicadores, levando-a a relativizar suas conclusões e análises. 


\section{5 - CONTINUANDO O DEBATE: PONTOS DE PARTIDA}

A polêmica sobre a temática em questão fica constatada, mas também verificamos a possibilidade de conhecimento e práticas a serem promovidos de forma interdisciplinar no campo da Saúde Pública. Para isso, ressaltamos, de início, pressupostos para que se continue o aprofundamento do assunto.

Entre os pressupostos básicos para uma continuidade da discussão, destacamos que a interdisciplinaridade é ao mesmo tempo uma questão de saber e de poder. Esse pressuposto pode ser visto, pelo menos, a partir de duas dimensões. De um lado, podemos entender que um campo científico delimita o conhecimento para melhor exercer domínio sobre esse, enquanto objeto de estudo. Por outro lado, quanto maior for a fragmentação dos recortes, menor poderá ser a possibilidade do exercício do poder num conjunto maior do conhecimento.

Outro pressuposto se refere ao campo epistemológico propriamente dito. Esse pressuposto se vincula a suposição de que o avanço no campo da interdisciplinaridade pode ser contextualizado a partir de princípios da lógica de complexidade. Segundo Morin ${ }^{17}$, complexidade não é necessariamente sinônimo de complicação. "É o problema da dificuldade de pensar, porque o pensamento é um combate com e contra a lógica, com e contra as palavras, com e contra o conceito" $\left(\mathrm{MORIN}^{17}\right)$. Pensar em direção da complexidade significa o não reducionismo. Significa entender que o pensamento mutilante, como observa Morin, por não conseguir ordenar informações e saberes, é enganoso e conduz a ações mutilantes. A lógica da complexidade, partindo de diferentes dimensões, procura tornar o pensamento mais complexo para dar conta da produção do conhecimento.

Para que se avance na questão da interdisciplinaridade, é importante lembrarmos que essa não anula a disciplinaridade. Assim como não significa a justaposição de saberes, também não anula a especificidade de cada campo de saber. Ela, antes de tudo, implica numa consciência dos limites e das potencialidades de cada campo de saber para que possa haver uma abertura em direção de um fazer coletivo.

Um fazer interdisciplinar, por outro lado, pode envolver recortes no conjunto do conhecimento. O problema é como recortar e para que recortar. Um recorte deve ser sempre visto como tal e não pode substituir o todo.

Concluímos que a interdisciplinaridade no campo da Saúde Pública alcança um status de necessidade interna diante da complexidade que o problema da Saúde impõe. A situação de miséria, a alarmante concentração de bens e oportunidades e quase exclusão total de cidadania para imensa maioria da população brasileira dão maior 
dimensão e gravidade a necessidade de abordagens de saúde que sejam eficazes, competentes e que tenham uma face humana.

\section{INTERDISCIPLINARITY ON PUBLIC HEALTH: A FIELD IN CONSTRUCTION}

This article, based on a literature review, aims to discuss the interdisciplinarity on Public Health (its needs, barriers for implementation and possibilities). Therefore, initially, the authors present a discuss on conceptual and historical terms, that explains the subject. In this part, it is discussed the process of inclusion and exclusion of interdisciplinarity on Public Health, as well as the different dimension of it. Subsequently it is related an interdisciplinary experience on Public Health. Finally, the authors concluded that the interdisciplinary is extremely necessary to Public Health due to the complexity of its object of study.

UNITERMS: interdisciplinarity, Public Health

\section{INTERDISCIPLINARIDAD EN LA SALUD PÚBLICA: UM CAMPO EN CONSTRUCCIÓN}

El presente artículo, basado en una revisión bibliográfica, tiene como objetivo discutir la cuestión de la interdisciplinaridad en el campo de la Salud Pública (su necesidad, obstáculos a su implementación y posibilidades). Para tanto inicialmente, es presentado un debate en términos conceptuales e históricos que explica claramente la temática. En este segmento es discutida la trayectoria de inclusión y exclusión de la interdisciplinaridad en el campo de la Salud Pública así como las diferentes dimensiones de la misma. A continuación es relatada una experiencia interdisciplinar en el campo de la Salud Pública. Finalmente se concluye que la interdisciplinaridad es imprescindible en el campo de la Salud Pública dada la complejidad de su objeto.

UNITERMOS: interdisciplinaridad, Salud Pública 


\section{REFERÊNCIAS BIBLIOGRÁFICAS}

01. ABEM. Ciências sociais e biológicas no curso médico. Enfoque interdisciplinar. OPAS/ABEM. 1989. (mimeo)

02. BIRMAN, J. Apresentação: interpretação e representação na saúde coletiva. PhysisRevista de Saúde Coletiva, v. 1, n. 2, p. 7-22, 1991.

03. CARNEIRO LEÃO, E. Para uma crítica da interdisciplinaridade. Revista Tempo Brasileiro. 1991. (no prelo).

04. FOUCAULT, M. História da sexualidade I: a vontade do saber. Rio de Janeiro: Graal. 1985a.

05. FOUCAULT, M. História da sexualidade II: o uso dos prazeres. Rio de Janeiro: Graal. (Biblioteca de Filosofia e História das Ciências; v.n. 15). 1985b.

06. FOUCAUL T, M. História da sexualidade 111: o cuidado de si. Rio de Janeiro: Graal. (Biblioteca de Filosofia e História das Ciências; v. 16). 1985c.

07. FRENK, J. La nueva salud pública. In: La crisis de la Salud Pública: reflexiones para el debate. (Organização Pan-americana de la Salud), p. 75-93, Washington, D.C. (EUA): OPAS (Publicación Científica, 540). 1992.

08. GARCIA, J.C. Pensamento social em saúde na América Latina. (Everardo D. Nunes org.) São Paulo: Cortez. (Coleção Pensamento Social e Saúde; 5). 1989.

09. GUSDORF, G. Prefácio. In: Interdisciplinaridade e patologia do saber. (Japiassu, H.) Rio de Janeiro: Imago. 1976.

10. HERLZLICH \& PIERRET. Uma doença no espaço público. Physis-Revista de Saúde Coletiva, v.2, n. 1, p. 7-35. 1992.

11. JAPIASSU, H. Interdisciplinaridade e patologia do saber. Rio de Janeiro: Imago. 1976.

12. McELROY, A., TOWNSEND, P. K. Interdisciplinary research in health problems. Medical Anthropology in Ecological Perspective. Colorado: Westview Press, 2. ed. 1989.

13. MINAYO. Interdisciplinaridade: uma questão que atravessa o saber, o poder e o mundo vivido. Medicina, v. 24, n. 2, p. 70-77. 1991.

14. Interdisciplinaridade na compreensão da violência e saúde. 1991. (mimeo).

15. Interdisciplinaridade: funcionalidade ou utopia? 1993. (no prelo).

16. MINAYO, M.C.S., SOUZA, E.R. Violência para todos. Cadernos de Saúde Pública, v. 9, n. 1, p. 65-78. 1993. 
17. MORIN, E. O problema epistemológico da complexidade. Portugal: Publicações Europa-América, s.d.

18. RUFFINO-NETO, A. Qualidade de vida: compromisso histórico da epidemiologia. Saúde em debate, 35, p. 63-67. 1992.

19. SOUZA, E.R., ASSIS, S.G., DESLANDES, S.F. Pensando a violência na saúde coletiva: algumas reflexões a partir da epidemiologia e da sociologia. 1992. (mimeo). 